\title{
ATRIBUTOS QUÍMICOS DO SOLO E PRODUÇÃO DO FEIJOEIRO COM A APLICAÇÃO DE CALCÁRIO E MANGANÊS ${ }^{(1)}$
}

\author{
Reges Heinrichs ${ }^{(2)}$, Adônis Moreira ${ }^{(3)}$, Paulo Alexandre Monteiro de \\ Figueiredo $^{(2)}$ \& Eurípedes Malavolta ${ }^{\dagger(4)}$
}

\begin{abstract}
RESUMO
O feijão (Phaseolus vulgaris L.) constitui a base alimentar da população brasileira. Muitos fatores determinam a baixa produtividade do feijoeiro, desde problemas políticos até fatores técnicos, dentre eles a adubação e nutrição. $O$ objetivo foi avaliar os atributos químicos do solo e produção do feijoeiro (cv. Pérola) de acordo com a aplicação de calagem e Mn. O experimento foi realizado em vasos com Latossolo Vermelho-Amarelo distrófico típico fase cerrado, em delineamento inteiramente casualizado com três repetições, em esquema fatorial $2 \times 6$, envolvendo duas doses de uma mistura de $\mathrm{CaCO}_{3}$ e $\mathrm{MgCO}_{3}$, na relação molar 3:1 (de calcário, calculadas) para elevar a saturação por base para $50 \%$ e para $70 \%$ e seis doses de $\mathrm{Mn}\left(0,20,40,60,80 \mathrm{e} 100 \mathrm{mg} \mathrm{dm}^{-3}\right)$. Na análise dos resultados, verificouse decréscimo no teor foliar de Mn de acordo com o aumento da saturação por base, não sendo observado o mesmo efeito no solo após o cultivo. O teor de Mn no solo para produção máxima de grãos mostrou-se semelhante para saturação por base de 50 e $70 \%$; no entanto, a dose do micronutriente aplicada para essa produção foi de $28 \mathrm{mg} \mathrm{dm}^{-3}$ e $57 \mathrm{mg} \mathrm{dm}^{-3}$, respectivamente.
\end{abstract}

Termos de indexação: Phaseolus vulgaris, adubação, nutrição de plantas, saturação por base.

\footnotetext{
(1) Recebido para publicação em janeiro de 2007 e aprovado em fevereiro de 2008.

(2) Professor do Campus Experimental de Dracena, Universidade Estadual Paulista - UNESP. Rodovia SP 294, km 651, CEP 17900000 Dracena (SP). E-mails: reges@dracena.unesp.br, paulofigueiredo@dracena.unesp.br

(3) Pesquisador da Embrapa Pecuária Sudeste - CPPSE. Caixa Postal 339, CEP 13560-970 São Carlos (SP). Email: adonis@cppse.embrapa.br

${ }^{(4)}$ Professor do Centro de Energia Nuclear na Agricultura, Universidade de São Paulo - CENA/USP. Av. Centenário 303, CEP 13400-970 Piracicaba (SP). E-mail: euri@cena.usp.br
} 


\title{
SUMMARY: SOIL CHEMICAL ATRIBUTES AND COMMON BEAN YIELD AS AFFECTED BY LIME AND MANGANESE RATES
}

\begin{abstract}
Common bean is one of the most important staples in Brazil. The objective of this study was to evaluate the common bean cv. Pérola yield and changes in soil chemical attributes as influenced by liming and manganese rates. The experiment was carried out in pots containing dystrophic Red Yellow Latosol (Oxisol). Treatments consisted of a $2 \times 6$ factorial combination of two limestone $\left(\mathrm{CO}_{3}\right.$ and $\mathrm{MgCO}_{3}$ in a 3:1 molar ratio) rates, calculated to increase base saturation to 50 and $70 \%$, respectively, and six Mn rates $(0,20$, 40, 60, 80 and $100 \mathrm{mg} \mathrm{kg}^{-1}$ ), using $\mathrm{MnSO}_{4} \cdot \mathrm{H}_{2} \mathrm{O}$ as source. There were three repetitions. Results showed that a higher base saturation reduced leaf Mn concentration, but soil Mn concentration after harvest was not altered. The soil Mn concentration sufficient to reach the maximum grain yield was similar for both 50 and $70 \%$ base saturation, but the doses to reach such critical soil concentration were 28 and $57 \mathrm{mg} \mathrm{dm}^{-3}$, respectively.
\end{abstract}

Index terms: Phaseolus vulgaris, manure, plant nutrition, base saturation.

\section{INTRODUÇÃO}

O feijão (Phaseolus vulgaris L.) constitui a base alimentar da população brasileira. A produção nacional de feijão está em torno de 2,9 milhões de toneladas, com produtividade média de $745 \mathrm{~kg} \mathrm{ha}^{-1}$ (IBGE, 2007).

Muitos fatores determinam a baixa produtividade do feijoeiro, desde problemas políticos até fatores técnicos, dentre os quais se destacam a adubação e nutrição. O uso racional de corretivos e fertilizantes é uma das premissas necessárias para o sucesso na produção. A adubação é um componente importante do sistema de produção, tanto pelo aumento de produtividade que pode proporcionar como pelo custo que representa (Souza, 2000). Para tanto, são necessárias pesquisas, principalmente com micronutrientes, que ainda são escassas na literatura referente à cultura do feijoeiro.

$\mathrm{O} \mathrm{pH}$ do solo é o primeiro ponto a ser trabalhado para a produção de feijão, visto que somente após a calagem pode-se ter noção da real disponibilidade de nutrientes (Oliveira et al., 1996). Com o índice $\mathrm{pH}$ de 5,5 a 6,5 , os nutrientes encontram-se em disponibilidade máxima ( $\mathrm{N}, \mathrm{P}, \mathrm{K}, \mathrm{Ca}, \mathrm{Mg}, \mathrm{S}$ e B) ou adequada ( $\mathrm{Cu}, \mathrm{Fe}, \mathrm{Mn}$, Mo e $\mathrm{Zn}$ ), enquanto o teor de $\mathrm{Al}$ em concentração tóxica é reduzido ou mínimo. Além dos benefícios relacionados com a disponibilidade de nutrientes, a calagem melhora as propriedades físicas do solo, favorecendo o desenvolvimento das raízes e ampliando a capacidade de a planta retirar água e nutrientes do solo (Vieira, 1998). Segundo Rosolem (1996), resultados de diversas pesquisas revelam que a máxima produtividade de feijão ocorre quando o $\mathrm{pH}$ do solo medido em água encontra-se entre 6,0 e 7,0.

Condições de solo como elevado $\mathrm{pH}$ e ambiente de oxidação estimulam a formação de $\mathrm{MnO}_{2}$ e reduzem a disponibilidade de Mn para as plantas (Marschner, 1995; Christenson et al., 2000; Mengel \& Kirkby, 2001). Malavolta \& Kliemann (1985) relatam que a cada unidade de $\mathrm{pH}$ que se eleva, a concentração de $\mathrm{Mn}^{2+}$ na solução diminui 100 vezes. Moraes et al. (1998) verificaram que a prática da calagem ocasionou decréscimos nos teores foliares de Mn no feijoeiro; entretanto, este efeito não foi observado no solo. Segundo os autores, é provável que a reação do calcário, provocando aumentos nos valores $\mathrm{pH}$, tenha possibilitado a diminuição da forma solúvel $\left(\mathrm{Mn}^{2+}\right)$ e aumento das formas não absorvidas pelas plantas $\left(\mathrm{Mn}^{3+} \mathrm{e} \mathrm{Mn}^{4+}\right)$.

A aplicação de uma fonte solúvel pode ser usada para aumentar a disponibilidade de Mn para as plantas; no entanto, aumentar dessa forma o teor de Mn trocável não é economicamente viável, pelo fato de $\mathrm{Mn}^{2+}$ oxidar-se a $\mathrm{Mn}^{4+}$ e precipitar como óxido (Borkert, 1991). O mais importante fator que governa a disponibilidade do Mn para as plantas, nas condições normais, é a reação do solo, pois a absorção desse elemento decresce com a elevação do $\mathrm{pH}$, em decorrência da formação de hidróxidos e óxidos de Mn de baixa solubilidade (Oliveira Júnior et al., 2000).

A tolerância ao Mn em concentrações tóxicas de seis genótipos de feijoeiros, em três condições de crescimento: solução nutritiva, areia e solo com aplicação de Mn, foi estudada por González \& Lynch (1999). Os autores verificaram que alguns genótipos desenvolveram-se muito bem em solução nutritiva e areia; no entanto, no solo com Mn, houve sensível redução na produção de grãos. Evidencia-se, então, a importância de estudos em solução nutritiva para identificação de genótipos tolerantes a teores elevados de Mn; entretanto, o desenvolvimento destas plantas em solos com alto teor do micronutrientes não é garantido pelas interações edáficas que possam ocorrer (Rao, 2002).

Christenson et al. (2000), estudando a absorção de nutrientes sob aplicação de calcário, verificaram 
redução na concentração de $\mathrm{Mn}$ no feijoeiro com o aumento da dose. No entanto, a produção não foi afetada, relatando a necessidade do estudo detalhado das condições de $\mathrm{pH}$ do solo e o estado nutricional das plantas relacionado com a produção.

Mediante o descrito, foi realizado o experimento com o objetivo de avaliar os atributos químicos do solo e a produção do feijoeiro (cv. Pérola) com aplicação da calagem e Mn.

\section{MATERIAL E MÉTODOS}

O experimento foi realizado em condições de casa de vegetação do Centro de Energia Nuclear na Agricultura (Cena/USP), localizado no Município de Piracicaba, nas coordenadas geográficas de $22^{\circ}$ 42 ' 30 ” LS e $47^{\circ} 38^{\prime} 00$ ” LW, Estado de São Paulo.

O solo utilizado foi classificado como Latossolo Vermelho-Amarelo distrófico típico fase cerrado (Embrapa, 1999). A coleta foi feita na profundidade de 0-20 cm, formando-se uma amostra composta, destorroada, homogeneizada, seca ao ar e passada em peneira com malha de $2 \mathrm{~mm}$ de abertura. As características químicas com os respectivos extratores estão apresentados no quadro 1 e com a seguinte composição granulométrica: 76 \% de argila; $11 \%$ de silte; $13 \%$ de areia.
O delineamento experimental foi inteiramente casualizado, com três repetições, em esquema fatorial $2 \times 6$, envolvendo duas doses de calcário, calculadas para elevar a saturação por base (V) para 50 e para $70 \%$ (Quaggio et al., 1985). As fontes utilizadas foram $\mathrm{CaCO}_{3}$ e $\mathrm{MgCO}_{3}$, reagentes p.a., na relação molar de $3: 1$ e seis doses de $\operatorname{Mn}\left(0,20,40,60,80\right.$ e $100 \mathrm{mg} \mathrm{dm}^{-3}$ de solo), perfazendo um total de 12 combinações.

Para cada parcela, foram colocados $3 \mathrm{dm}^{3}$ de terra em uma bandeja de plástico e 30 dias após a correção da acidez foram aplicadas as seguintes concentrações de nutrientes $\left(\mathrm{mg} \mathrm{dm}^{-3}\right): 130$ de N; 200 de P; 180 de $\mathrm{K} ; 0,5$ de B; 0,05 de Co; 1,0 de Cu; 0,05 de Mo; 0,05 de $\mathrm{Ni}$; e 3,0 de Zn. Para obter essas concentrações de nutrientes, foram utilizadas as seguintes fontes: $\mathrm{NH}_{4} \mathrm{NO}_{3}, \mathrm{Ca}\left(\mathrm{H}_{2} \mathrm{PO}_{4}\right)_{2}, \mathrm{~K}_{2} \mathrm{SO}_{4}, \mathrm{H}_{3} \mathrm{BO}_{3}, \mathrm{CoCl}_{2}, \mathrm{CuSO}_{4}$, $\mathrm{H}_{2} \mathrm{MoO}_{4}, \mathrm{NiSO}_{4} \mathrm{e} \mathrm{ZnSO}_{4}$. Para o Mn, a fonte utilizada foi o $\mathrm{MnSO}_{4}$ na dose conforme cada tratamento com posterior homogeneização. Em seguida, a terra foi transferida para os respectivos vasos e, após sete dias, o solo foi amostrado para análise e a semeadura do feijão (Phaseolus vulgaris L.) cv. Pérola foi efetuada.

A umidade do solo foi mantida próxima de $80 \%$ da capacidade de campo mediante a irrigação diária com água desionizada para compensar as perdas por evapotranspiração.

A dose de $\mathrm{N}$ foi parcelada em duas vezes, na semeadura e no estádio R5 (aparecimento dos primeiros botões em $50 \%$ das plantas), enquanto a

Quadro 1. Atributos químicos do solo após aplicação dos fertilizantes

\begin{tabular}{|c|c|c|c|c|c|c|c|c|c|c|c|c|c|}
\hline \multirow{3}{*}{ Característica } & \multirow{3}{*}{$\begin{array}{c}\text { Sem } \\
\text { calagem }\end{array}$} & \multicolumn{6}{|c|}{ Correção da saturação por base para 50 \% } & \multicolumn{6}{|c|}{ Correção da saturação por base para $70 \%$} \\
\hline & & \multicolumn{12}{|c|}{ Dose de $M n\left(\mathrm{mg} \mathrm{dm}^{-3}\right)$} \\
\hline & & $\mathbf{0}$ & 20 & 40 & 60 & 80 & 100 & $\mathbf{0}$ & 20 & 40 & 60 & 80 & 100 \\
\hline $\mathrm{pH}\left(\mathrm{CaCl}_{2}\right)$ & 4,2 & 4,8 & 4,9 & 5 & 4,9 & 4,6 & 4,8 & 5,4 & 5 & 5,3 & 5 & 5,1 & 5,0 \\
\hline $\operatorname{MO}\left(\mathrm{g} \mathrm{dm}^{-3}\right)$ & 28 & 28 & 30 & 30 & 31 & 30 & 31 & 29 & 28 & 29 & 30 & 29 & 27 \\
\hline $\mathrm{P}\left(\mathrm{mg} \mathrm{dm}^{-3}\right)$ & 4,0 & 88 & 104 & 85 & 110 & 98 & 112 & 93 & 86 & 82 & 85 & 86 & 90 \\
\hline $\mathrm{S}-\mathrm{SO}_{4}{ }^{2 \cdot}\left(\mathrm{g} \mathrm{dm}^{-3}\right)$ & 11 & 92 & 125 & 148 & 212 & 201 & 258 & 71 & 71 & 74 & 88 & 102 & 115 \\
\hline $\mathrm{K}^{+}\left(\mathrm{mmol}_{\mathrm{c}} \mathrm{dm}^{-3}\right)$ & 1,1 & 2,9 & 2,7 & 2,7 & 3,2 & 3 & 4,1 & 2,1 & 1,8 & 1,7 & 1,9 & 1,9 & 2,1 \\
\hline $\mathrm{Ca}^{2+}\left(\mathrm{mmol}_{\mathrm{c}} \mathrm{dm}^{-3}\right)$ & 11 & 22 & 28 & 30 & 34 & 23 & 28 & 31 & 26 & 27 & 27 & 28 & 32 \\
\hline $\mathrm{Mg}^{2+}\left(\mathrm{mmol}_{\mathrm{c}} \mathrm{dm}^{-3}\right)$ & 3 & 6 & 7 & 6 & 7 & 7 & 8 & 7 & 8 & 8 & 11 & 10 & 15 \\
\hline $\mathrm{Al}^{3+}\left(\mathrm{mmol}_{\mathrm{c}} \mathrm{dm}^{-3}\right)$ & 6 & 2 & 1 & 1 & 0 & 1 & 1 & 0 & 0 & 0 & 0 & 0 & 0 \\
\hline $\mathrm{H}+\mathrm{Al}\left(\mathrm{mmol}_{\mathrm{c}} \mathrm{dm}^{-3}\right)$ & 58 & 25 & 28 & 28 & 31 & 34 & 31 & 22 & 25 & 25 & 25 & 25 & 22 \\
\hline $\mathrm{SB}\left(\mathrm{mmol}_{\mathrm{c}} \mathrm{dm}^{-3}\right)$ & 15,1 & 30,9 & 37,7 & 38,7 & 44,2 & 33 & 40,1 & 40,1 & 35,8 & 36,7 & 39,9 & 39,9 & 49,1 \\
\hline $\mathrm{CTC}\left(\mathrm{mmol}_{\mathrm{c}} \mathrm{dm}^{-3}\right)$ & 73,1 & 55,9 & 65,7 & 66,7 & 75,2 & 67 & 71,1 & 62,1 & 60,8 & 61,7 & 64,9 & 64,9 & 71,1 \\
\hline $\mathrm{V}(\%)$ & 21 & 55 & 57 & 58 & 58 & 49 & 56 & 65 & 59 & 59 & 61 & 61 & 69 \\
\hline$m(\%)$ & 28 & 6 & 3 & 3 & 0 & 3 & 2 & 0 & 0 & 0 & 0 & 0 & 0 \\
\hline$B\left(\mathrm{mg} \mathrm{dm}^{-3}\right)$ & 0,25 & 0,24 & 0,2 & 0,23 & 0,25 & 0,27 & 0,27 & 0,15 & 0,13 & 0,16 & 0,25 & 0,13 & 0,11 \\
\hline $\mathrm{Cu}\left(\mathrm{mg} \mathrm{dm}^{-3}\right)$ & 0,8 & 1,2 & 1,2 & 1,1 & 1,2 & 1,1 & 1,1 & 1,1 & 1,1 & 1,3 & 1,2 & 1,1 & 1,1 \\
\hline $\mathrm{Fe}\left(\mathrm{mg} \mathrm{dm}^{-3}\right)$ & 75 & 35 & 34 & 34 & 41 & 48 & 43 & 34 & 32 & 34 & 31 & 33 & 30 \\
\hline $\mathrm{Mn}\left(\mathrm{mg} \mathrm{dm}^{-3}\right)$ & 1,2 & 1,4 & 7,6 & 15 & 37 & 61,6 & 81 & 2,4 & 8 & 14,4 & 18,2 & 24 & 34,2 \\
\hline $\mathrm{Zn}\left(\mathrm{mg} \mathrm{dm}^{-3}\right)$ & 0,3 & 0,8 & 0,8 & 0,7 & 0,8 & 0,9 & 0,9 & 0,7 & 0,6 & 0,7 & 0,7 & 0,6 & 0,7 \\
\hline
\end{tabular}

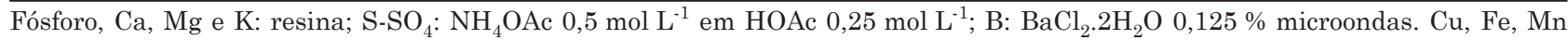
e Zn: DTPA TEA pH 7,3. 
dose de $\mathrm{K}$ foi dividida em três aplicações: na semeadura, no estádio R5 e R8 (primeira vagem cheia de semente em $50 \%$ das plantas).

As sementes foram inoculadas com Rhizobium específico e, em seguida, foram semeadas seis sementes por vaso. Quando as plantas atingiram o estádio V3 (primeiro trifólio), foi realizado o desbaste, deixandose duas plantas uniformes.

No estádio R6 (abertura das primeiras flores), foram coletados o primeiro e o segundo trifólio com as folhas totalmente expandidas para diagnose foliar. No estádio R9 (maturação), os grãos foram colhidos e o solo novamente amostrado para análise. As plantas foram secas a $65^{\circ} \mathrm{C}$ e, posteriormente, moídas para determinação dos teores de $\mathrm{Ca}, \mathrm{Mg}$ e $\mathrm{Mn}$ (Malavolta et al., 1997). No solo, foram realizadas as análises utilizando os seguintes métodos: $\mathrm{P}, \mathrm{K}$, Ca e $\mathrm{Mg}$ por

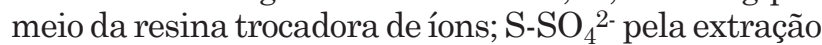
com solução de fosfato de $\mathrm{Ca} ; \mathrm{pH}$ em $\mathrm{CaCl}_{2}$; matéria orgânica por colorimetria; $\mathrm{H}+\mathrm{Al}$ com solução-tampão SMP; Al em KCl. Em relação aos micronutrientes, o boro foi extraído via água quente e $\mathrm{Cu}, \mathrm{Fe}, \mathrm{Mn}$ e Zn em DTPA (Raij et al., 2001).

Os resultados de análises de solo e planta foram avaliados estatisticamente mediante análise da variância, interações, comparação de médias pelo teste de Tukey a $5 \%$ e regressões (Pimentel-Gomes \& Garcia, 2002).

\section{RESULTADOS E DISCUSSÃO}

A aplicação dos carbonatos, calculada para elevar a saturação por base para $70 \%$, foi suficiente para eliminar a presença de $\mathrm{Al}$ em níveis tóxicos no solo, no entanto, o valor médio foi de $62 \%$ (Quadro 1) e ficando em torno de $55 \%$, quando a saturação por base foi calculada para atingir $50 \%$, observando-se pequena presença do teor de $\mathrm{Al}$ trocável. Os demais nutrientes estão dentro da faixa considerada adequada para a cultura do feijoeiro (Ambrosano, 1996), exceto o Mn, quando da aplicação de doses maiores que $20 \mathrm{mg} \mathrm{dm}^{-3}$.

No quadro 2, observa-se interação significativa nos valores da soma de bases (SB), capacidade de troca de cátions (CTC) e saturação por bases (V), destacandose os tratamentos com doses acima de $60 \mathrm{mg} \mathrm{dm}^{-3} \mathrm{de}$ $\mathrm{Mn}$ e V corrigido para 70 \% que apresentaram maiores valores.

Na média das saturações por base, os teores de $\mathrm{Ca}, \mathrm{Mg}, \mathrm{SB}, \mathrm{CTC}, \mathrm{V}, \mathrm{pH}$ e $\mathrm{SO}_{4}^{-2}$ foram maiores na correção para $70 \%$ em relação aos tratamentos com correção para 50 \% (Quadros 2 e 3). Resultado esperado, uma vez que com a calagem os elementos $\mathrm{Ca}$ e $\mathrm{Mg}$ são fornecidos em maior quantidade. De forma inversa, os teores de $\mathrm{Al}, \mathrm{H}+\mathrm{Al}$, saturação por $\mathrm{Al}(\mathrm{m}), \mathrm{Cu}, \mathrm{Fe}$ e $\mathrm{Zn}$ (Quadros 2 e 3) reduziram com a elevação da saturação por bases. Estes resultados são sustentados, conforme descreve Raij (1991), com a correção da acidez do solo elevando o $\mathrm{pH}$ acima de 5,5, ocorrendo a neutralização do $\mathrm{Al}$, levado à precipitação na forma de hidróxido e, conseqüentemente, a saturação por $\mathrm{Al}$ aproxima-se de zero para uma saturação por base em torno de $50 \%$. Cabe salientar que essas relações nem sempre são válidas, sobretudo, para amostras de solo de camadas mais profundas ou materiais de carga variável. Da mesma forma a disponibilidade dos micronutrientes $\mathrm{Cu}, \mathrm{Fe}, \mathrm{Zn}$ foi reduzida, eles são insolubilizados, provavelmente, como óxidos (Malavolta, 1980), os quais, embora apresentem tendência decrescente de disponibilidade, encontramse em concentrações suficientes para suprir as necessidades nutricionais do feijoeiro.

Com aplicação de Mn o teor no solo variou de forma direta com a dose aplicada, variando de 1,4 a $81,0 \mathrm{mg} \mathrm{dm}^{-3}$ e de 2,4 a $34,2 \mathrm{mg} \mathrm{dm}^{-3}$ (Quadro 1) para as saturações por base de 50 e $70 \%$, respectivamente, e após um cultivo não se observou variação significativa na concentração com a dose de carbonatos (Quadro 3), corroborando os resultados de Moraes (1998). Os teores médios de Cu, Fe e Zn no solo após um cultivo reduziram à medida que a dose de $\mathrm{Mn}$ aplicada aumentou.

No quadro 4, estão compilados os teores de $\mathrm{Ca}, \mathrm{Mg}$ e Mn encontrados nas folhas diagnose do feijoeiro por ocasião do início do florescimento. De modo geral, em todos os tratamentos, exceto no tratamento com saturação por base corrigida para $50 \%$ e a dose de $100 \mathrm{mg} \mathrm{dm}^{-3}$ de $\mathrm{Mn}$, os teores estão dentro da faixa considerada adequada por Ambrosano et al. (1996) e Malavolta et al. (1997). Cabe salientar que, para o $\mathrm{Mn}$, a faixa considerada adequada para diagnose foliar no feijoeiro é muito ampla, variando de 30 a $300 \mathrm{mg} \mathrm{kg}^{-1}$.

$\mathrm{Na}$ análise de interação da aplicação de calcário e $\mathrm{Mn}$, o teor de $\mathrm{Mg}$ na folha diagnose apresentou significância. As maiores concentrações de Mg foram encontradas nos tratamentos em que a saturação por base foi corrigida para $70 \%$, até à dose de $40 \mathrm{mg} \mathrm{dm}^{-3}$ de Mn aplicado no solo. Na saturação por base de $50 \%$, observou-se que doses altas de $\mathrm{Mn}$ proporcionaram maior acúmulo de $\mathrm{Mg}$ na folha diagnose. Uma possível explicação pode ser atribuída à semelhança entre as funções do Mn na planta e do $\mathrm{Mg}^{2+}$; os dois íons formam pontes entre a ATP e as enzimas transferidoras de grupos fosfoquinase e fosfotransferase. No ciclo dos ácidos tricarboxílicos, operam descarboxilases e desigrogenase ativadas por $\mathrm{Mn}^{2+}$, em algumas o $\mathrm{Mg}^{2+}$ pode substituí-lo, aumentando a concentração do macronutriente.

Na média das saturações por base estudadas, os teores de $\mathrm{Ca}$ e $\mathrm{Mg}$ na folha diagnose seguiram a tendência observada no solo; à medida que aumentou a dose de carbonatos, os dois macronutrientes apresentaram maior concentração, enquanto na média das doses de Mn não houve efeito significativo nos valores de macronutrientes. 
Quadro 2. Interação entre doses de manganês e saturação por base nos atributos químicos do solo, após o cultivo do feijoeiro

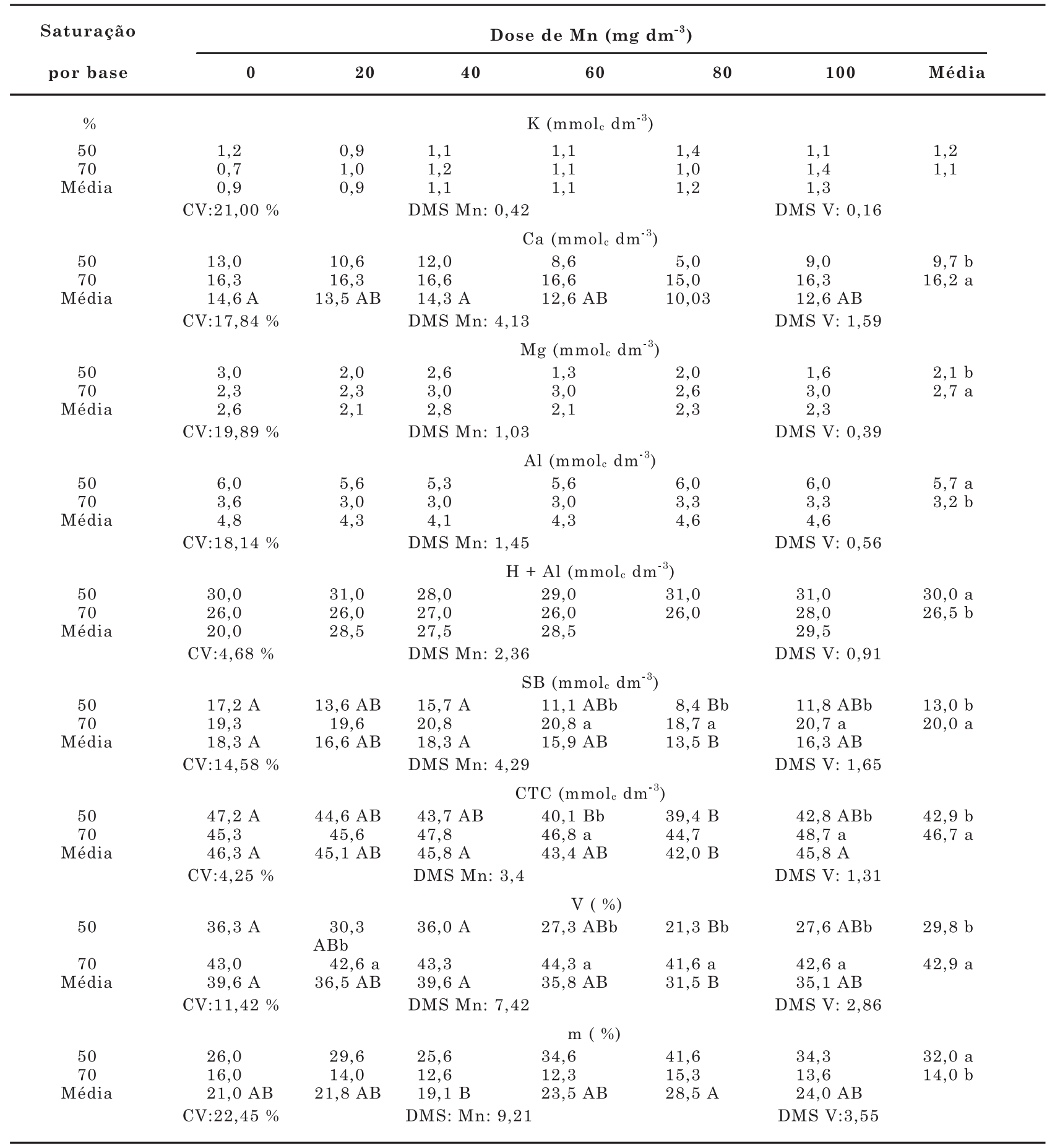

Médias seguidas por letras distintas, minúsculas, na coluna, e maiúsculas, na linha, diferem entre si pelo teste de Tukey a $5 \%$. K, Ca e Mg: extraído com resina trocadora de íons.

Os teores de Mn diminuíram com a calagem, seguindo a tendência de redução da disponibilidade dos micronutrientes de acordo com o aumento do $\mathrm{pH}$ (Malavolta, 1980). Na média das doses de Mn, bem como na interação com a calagem, houve efeito apenas no teor do próprio micronutriente, apresentando relação direta entre a dose aplicada e o teor na folha. A partir de $60 \mathrm{mg} \mathrm{dm}^{-3}$ de $\mathrm{Mn}$, os valores do micronutriente foram maiores na saturação por base de $50 \%$, evidenciando, mais uma vez o efeito do $\mathrm{pH}$ 
Quadro 3. Interação entre doses de manganês e saturação por base nos valores de pH, matéria orgânica, fósforo, enxofre, boro, cobre, ferro, manganês e zinco no solo, após o cultivo do feijoeiro

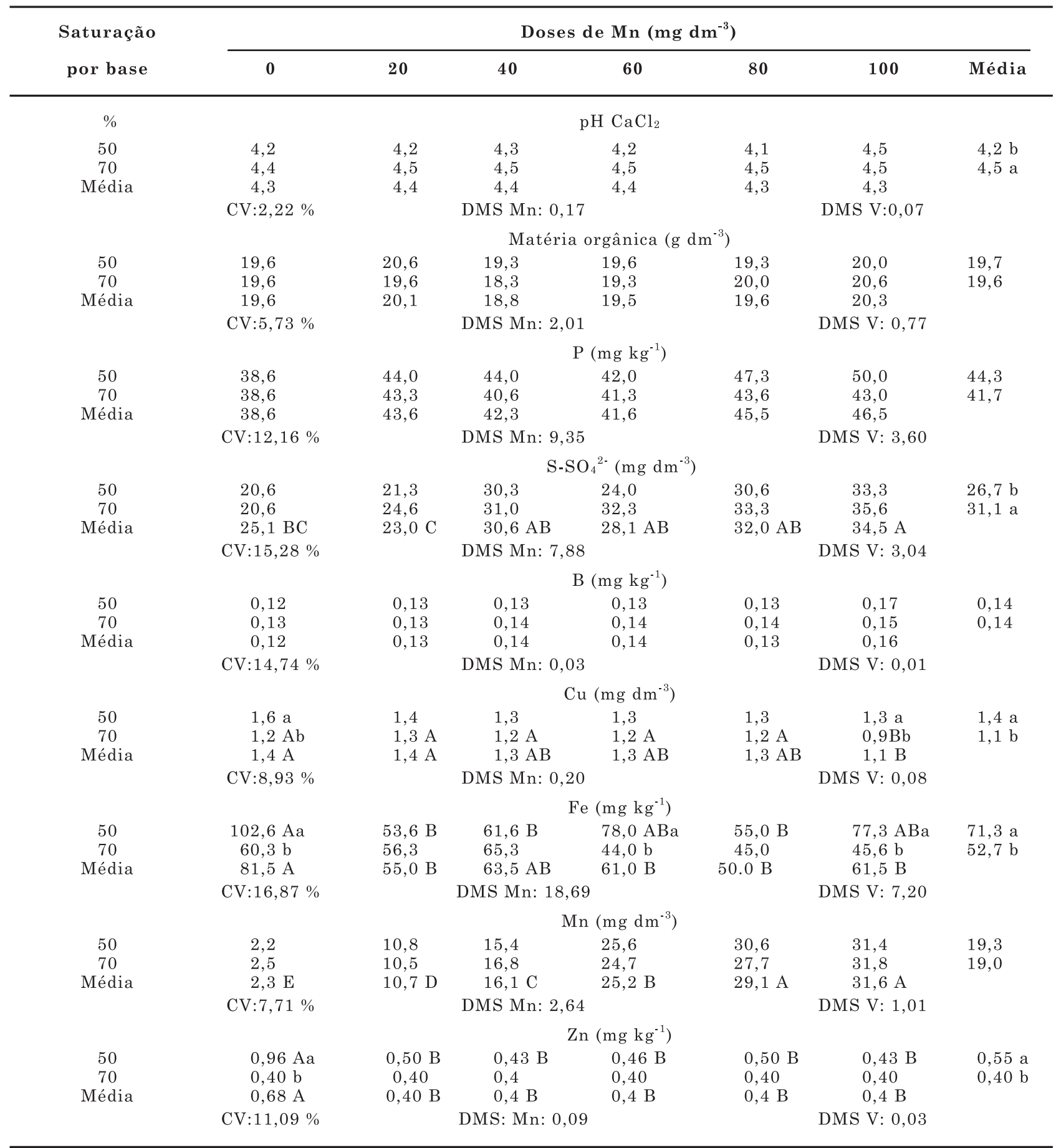

Médias seguidas por letras distintas, minúsculas, na coluna, e maiúsculas, na linha, diferem entre si pelo teste de Tukey a $5 \%$. P: Extraído com resina trocadora de íons; $\mathrm{S}_{-} \mathrm{SO}_{4}{ }^{2-}$ pela extração com solução de fosfato de cálcio; $\mathrm{B}$ : $\mathrm{BaCl}_{2} \cdot 2 \mathrm{H}_{2} \mathrm{O} 0,125$ dag $\mathrm{L}^{-1}$ microondas; $\mathrm{Cu}, \mathrm{Fe}, \mathrm{Mn}$ e Zn: DTPA TEA pH 7,3.

na disponibilidade do elemento, enquanto nas doses menores de Mn os teores foliares não variaram entre as duas saturações por bases. A variação entre a dose 0 a $100 \mathrm{mg} \mathrm{dm}^{-3}$ de $\mathrm{Mn}$ com V de $50 \%$ foi de
$382,4 \mathrm{mg} \mathrm{kg}^{-1}$, enquanto para $\mathrm{V}$ de $70 \%$ a variação foi de $89 \mathrm{mg} \mathrm{dm}^{-3}$, comprovando que uma alternativa para minimizar o seu efeito tóxico, reduzindo sua absorção, é a calagem (Lopes, 1983). 
$\mathrm{Na}$ saturação por base de $50 \%$, a dose de $100 \mathrm{mg} \mathrm{dm}^{-3}$ de Mn proporcionou redução na produção de grãos, quando essa foi elevada a 70 \% não foi observado efeito significativo. Confirmando as descrições de Ambrosano et al. (1996), Malavolta et al. (1997) e Reuter \& Robinson (1997) há uma faixa muito ampla no teor foliar do micronutriente que não afeta a produção de grãos.
Na figura 1, estão apresentadas as relações entre teores e doses de Mn e produção de grãos. Para a saturação por base de $50 \%$, o teor na folha diagnose e o teor no solo, para produção máxima, foram, respectivamente, de $5 \mathrm{mg} \mathrm{kg}^{-1}$ e $17,77 \mathrm{mg} \mathrm{dm}^{-3}$, enquanto, para saturação por base de $70 \%$, os valores foram, respectivamente, de $71 \mathrm{mg} \mathrm{kg}^{-1}$ e $19,57 \mathrm{mg} \mathrm{dm}^{-3}$. A saturação por base recomendada para o feijoeiro por

Quadro 4. Teores de cálcio, magnésio e manganês nas folhas diagnose do feijoeiro

\begin{tabular}{|c|c|c|c|c|c|c|c|}
\hline \multirow{2}{*}{$\begin{array}{c}\text { Saturação } \\
\text { por base }\end{array}$} & \multicolumn{7}{|c|}{ Doses de $\operatorname{Mn}\left(\mathrm{mg} \mathrm{dm}^{-3}\right)$} \\
\hline & 0 & 20 & 40 & 60 & 80 & 100 & Média \\
\hline$\%$ & \multicolumn{7}{|c|}{$\mathrm{Ca}\left(\mathrm{g} \mathrm{kg}^{-1}\right)$} \\
\hline 50 & 13,7 & 14,1 & 14,6 & 15,0 & 13,0 & 14,5 & $14,1 \mathrm{~b}$ \\
\hline 70 & 17,4 & 15,2 & 17,2 & 16,0 & 15,5 & 17,1 & $16,4 \mathrm{a}$ \\
\hline \multirow[t]{3}{*}{ Média } & 15,5 & 14,7 & 15,9 & 15,5 & 14,2 & 15,8 & \\
\hline & CV:9,81\% & & DMS Mn: & & DMS V: 1,03 & & \\
\hline & \multicolumn{7}{|c|}{$\operatorname{Mg}\left(\mathrm{g} \mathrm{kg}^{-1}\right)$} \\
\hline 50 & $3,3 \mathrm{Bb}$ & $3,5 \mathrm{Bb}$ & $3,6 \mathrm{ABb}$ & $3,9 \mathrm{AB}$ & $4,5 \mathrm{~A}$ & $3,9 \mathrm{AB}$ & $3,8 \mathrm{~b}$ \\
\hline 70 & $4,8 \mathrm{a}$ & $4,6 \mathrm{a}$ & $4,9 \mathrm{a}$ & 4,7 & 4,6 & 4,3 & $4,6 \mathrm{a}$ \\
\hline \multirow[t]{3}{*}{ Média } & 4,1 & 4,0 & 4,2 & 4,3 & 4,5 & 4,1 & \\
\hline & CV: $8,14 \%$ & & DMS Mn: & & DMS V: 0,23 & & \\
\hline & \multicolumn{7}{|c|}{$\operatorname{Mn}\left(\mathrm{mg} \mathrm{kg}^{-1}\right)$} \\
\hline 50 & $39,6 \mathrm{E}$ & $68,3 \mathrm{D}$ & $90,3 \mathrm{D}$ & $153,3 \mathrm{Ca}$ & $281,3 \mathrm{Ba}$ & $422,0 \mathrm{Aa}$ & $175,8 \mathrm{a}$ \\
\hline 70 & $36,3 \mathrm{~B}$ & $44,0 \mathrm{~B}$ & $61,0 \mathrm{~B}$ & $59,3 \mathrm{Bb}$ & $65,3 \mathrm{Bb}$ & $125,3 \mathrm{Ab}$ & $65,2 \mathrm{~b}$ \\
\hline \multirow[t]{2}{*}{ Média } & $38,0 \mathrm{E}$ & $56,1 \mathrm{E}$ & $75,6 \mathrm{D}$ & $106,3 \mathrm{C}$ & $173,3 \mathrm{~B}$ & $273,6 \mathrm{~A}$ & \\
\hline & $\mathrm{CV}: 8,58 \%$ & & DMS Mn: & & DMS V: 7,11 & & \\
\hline
\end{tabular}

Médias seguidas por letras distintas, minúsculas, na coluna, e maiúsculas, na linha, diferem entre si pelo teste de Tukey a $5 \%$.
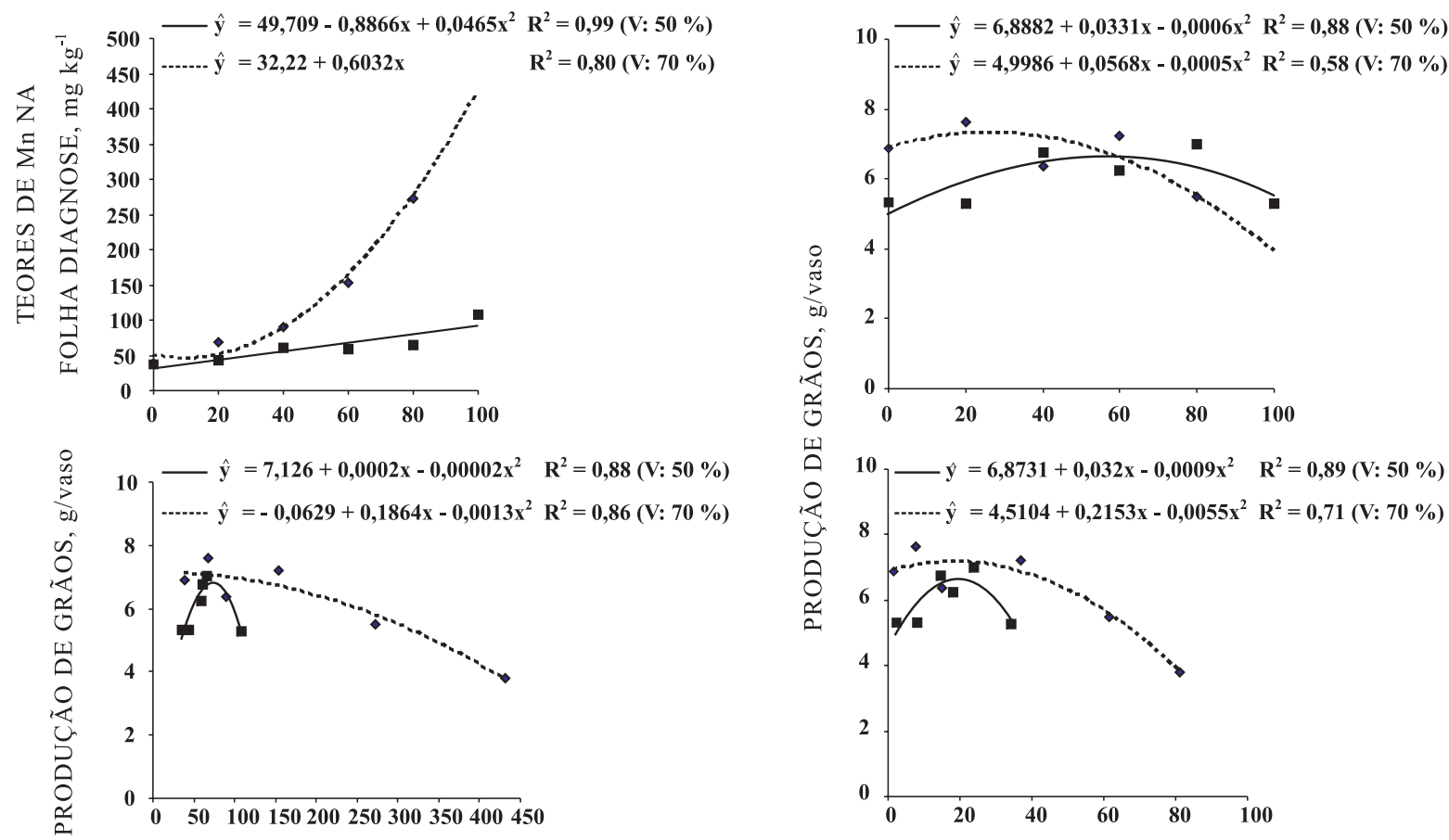

TEOR DE Mn NO SOLO, $\mathrm{mg} \mathrm{dm}^{-3}$

Figura 1. Relação entre doses e teores de manganês e produção de grãos de feijão. 
Ambrosano et al. (1996) é de $70 \%$, na qual o teor de Mn na folha usada para diagnose do presente estudo encontrou-se dentro da faixa considerada adequada segundo os mesmos autores. Observou-se redução na produção de grãos de feijão com o aumento do teor de Mn no solo, quando cultivado em solo com a correção da saturação por base para $50 \%$ e, quando esta foi elevada para $70 \%$, a variação na produção foi menor.

\section{CONCLUSÕES}

1. Ocorreu decréscimo no teor foliar de Mn no feijoeiro de acordo com o aumento da saturação por base, não sendo observado o mesmo efeito no solo após o cultivo.

2. Depois do cultivo do feijoeiro, o solo com saturação por base de $70 \%$ apresentou maiores valores de $\mathrm{pH}, \mathrm{Ca}^{2+}, \mathrm{Mg}^{2+}, \mathrm{SO}_{4}{ }^{2-}, \mathrm{SB}, \mathrm{CTC}$ e V e menores de $\mathrm{Al}, \mathrm{H}+\mathrm{Al}^{3+}, \mathrm{m}, \mathrm{Cu}, \mathrm{Fe}$ e $\mathrm{Zn}$ em relação à saturação por base de $50 \%$.

3. O teor de Mn disponível no solo $\left(18 \mathrm{mg} \mathrm{dm}^{-3}\right)$ para produção máxima de grãos foi semelhante para saturação por base de 50 e 70 \%; no entanto, a dose do microntriente aplicada para essa produção foi de $28 \mathrm{mg} \mathrm{dm}^{-3}$ e $57 \mathrm{mg} \mathrm{dm}^{-3}$, respectivamente.

\section{LITERATURA CITADA}

AMBROSANO, E.J.; TANAKA, R.T.; MASCARENHAS, H.A.A.; RAIJ, B.van; QUAGGIO, J.A. \& CANTARELLA, H Leguminosas e oleaginosas. In: RAIJ, B.van; CANTARELLA, H.; QUAGGIO, J.A. \& FURLANI, A.M.C., eds. Recomendações de adubação e calagem para o Estado de São Paulo. Campinas, Instituto Agronômico de Campinas, 1996. p.187-203 (Boletim Técnico, 100)

BORKERT, C.M. Manganês. In: FERREIRA, M.E. \& CRUZ, M.C.P., eds. Micronutrientes na agricultura. Piracicaba, Potafos/CNPq, 1991. p.173-189.

CHRISTENSON, D.R.; BRIMHALL, P.B.; HUBBELL, L. \& BRICKER, C.E. Yield of sugar beet, soybean, corn, field bean, and wheat as affected by lime application on alkaline soils. Comm. Soil Sci. Plant Anal., 31:1145-1154, 2000.

EMPRESA BRASILEIRA DE PESQUISA AGROPECUÁRIA EMBRAPA. Centro Nacional de pesquisa de Solos. Sistema brasileiro de classificação de solos. Brasília, 1999. $412 p$.

GONZÁLEZ, A. \& LYNCH, J. Tolerance of tropical common bean genotypes to manganese toxicity: Performance under different growing conditions. J. Plant Nutr., 22:511$525,1999$.

INSTITUTO BRASILEIRO DE GEOGRAGIA E ESTATÍSTICA - IBGE. Produção agrícola municipal: Cereais, leguminosas e oleaginosas 2004. Disponível em: <http:// www.ibge.gov.br> . Acesso em: 8 dez. de 2007.

LOPES, A.S. Solos sob "Cerrado": Características, propriedades e manejo. Piracicaba, Potafos, 1983. 162p.
MALAVOLTA, E. Elementos de nutrição mineral de plantas. Piracicaba, Agronômica Ceres, 1980. 251p.

MALAVOLTA, E. \& KLIEMANN, H.J. Desordens nutricionais no cerrado. Piracicaba, Potafos, 1985. 136p.

MALAVOLTA, E.; VITTI, G.C. \& OLIVEIRA, S.A. Avaliação do estado nutricional das plantas: princípios e aplicações. Piracicaba, Potafos, 1997. 319p.

MARSCHNER, H. Mineral nutrition of higher plants. London, Academic Press, 1995. 889p.

MENGEL, K. \& KIRKBY, E.A. Principles of plant nutrition. Bern, International Potash Institute, 2001. 849p.

MORAES, J.F.L.; BELLINGIERI, P.A.; FORNASIERI, FILHO, D. \& GALON, J.A. Efeito de doses de calcário e de gesso na cultura do feijoeiro (Phaseolus vulgaris L.) cv. Carioca 80. Sci. Agric., 55:438-447, 1998.

OLIVEIRA JÚNIOR, J.A.; MALAVOLTA, E. \& CABRAL, C.P. Efeitos do manganês sobre a soja cultivada em solo de cerrado do triângulo mineiro. Pesq. Agropec. Bras., 35:1629-1636, 2000.

OLIVEIRA, I.P.; ARAÚJO, R.S. \& DUTRA, L.G. Nutrição mineral e fixação biológica de nitrogênio. In: ARAUJO, R.S.; RAVA, C.A.; STONE, L.F. \& ZIMMERMANN, M.J.O., eds. Cultura do feijoeiro comum no Brasil. Piracicaba, Potafos, 1996. p.169-221.

PIMENTEL-GOMES, F. \& GARCIA, C.H. Estatística aplicada a experimentos agronômicos e florestais. Piracicaba, FEALQ, 2002. 309p.

QUAGGIO, J.A.; RAIJ, B.van \& MALAVOLTA, E. Alternative use of the SMP - Buffer solution to determine lime requirement of soil. Comm. Soil Sci. Plant Anal., 16:245260,1985 .

RAIJ, B.van. Fertilidade do solo e adubação. Piracicaba, Ceres, Potafos, 1991. 343p.

RAIJ, B.van.; ANDRADE, J.C.; CANTARELLA, H. \& QUAGGIO, J.A. Análise química para avaliação da fertilidade de solos tropicais. Campinas, Instituto Agronômico, 2001. 285p.

RAO, I.M. Role of physiology in improving crop adaptation to abiotic stresses in the tropics: The case of common bean and tropical forages. In: PESSARAKLI, M., ed. Handbook of plant and crop physiology. New York, Marcel Dekker, 2002. p.583-613.

REUTER, D.J. \& ROBINSON, J.B. Plant analysis: An interpretation manual. Melbourne, CSIRO Publishing, 1997. 572p.

ROSOLEM, C.A. Calagem e adubação mineral. In: ARAUJO, R.S.; RAVA, C.A.; STONE, L.F. \& ZIMMERMANN, M.J.O., eds. Cultura do feijoeiro comum no Brasil. Piracicaba, Potafos, 1996. p.353-390.

SOUZA, A.B. Populações de plantas, níveis de adubação e calagem para o feijoeiro (Phaseolus vulgaris L.) num solo de baixa fertilidade. Lavras, Universidade Federal de Lavras, 2000. 69p. (Tese de Doutorado)

VIEIRA, C. Adubação mineral e calagem. In: VIEIRA, C.; PAULA JR., T.J. \& BORÉM, A., eds. Feijão: Aspectos gerais e cultura do Estado de Minas Gerais. Viçosa, MG, Universidade Federal de Viçosa, 1998. p.123-151. 